\title{
The effects of CER training on the acquisition of a successive operant discrimination
}

\author{
JEROME FRIEMAN and DWIGHT WALKER \\ Kansas State University, Manhattan, Kansas 66506
}

\begin{abstract}
Following keypeck training to a chromatic stimulus, one group of pigeons was given CER training with a white vertical line superimposed on the key as the CS and shock as the US; a second group was given presentations of the CS only; a third group received shock only with no CS preceding it on the key; a fourth group received only the keypeck training with the chromatic stimulus. All groups then received identical training on a successive operant discrimination involving auditory stimuli. The CER subjects learned this discrimination faster than did subjects in the other three groups, which did not differ. The results extend the generality of conditions which facilitate the acquisition of successive operant discriminations.
\end{abstract}

In a number of experiments, it has been observed that successive operant discrimination training facilitates the acquisition of a subsequent successive operant discrimination along an orthogonal stimulus dimension. For example, Eck, Noel, and Thomas (1969) reported that pigeons given discrimination training between lines of of differing orientation acquired a subsequent wavelength discrimination faster than subjects given either nondifferential line-angle training or single-stimulus training with one line angle. This "positive transfer" effect has also been reported to follow errorless discrimination training (Keilitz \& Frieman, 1970), across stimulus modality (Tennant \& Bitterman, 1975; Thomas, Miller, \& Svinicki, 1971), across response class (Frieman \& Goyette, 1973), and following training on a conditional discrimination (Goyette \& Frieman, 1973).

The present experiment was an attempt to examine whether this positive transfer across stimulus dimensions would also occur following conditioned emotional response training (CER). In CER training, a subject is first trained to emit a response for positive reinforcement and then presented with repeated presentations of a conditioned stimulus (CS) followed by an unconditioned stimulus (US) of shock. The result of this training is that the subject's responding is suppressed during the presentation of the CS, but maintained during its absence. Thus, in the present experiment, the effects of CER training on the acquisition of a successive operant discrimination between stimuli not used in the CER training was investigated.

This paper is based on a dissertation submitted by Dwight Walker to the Graduate School, Kansas State University, in partial fulfillment of the requirements for the $\mathrm{PhD}$ degree. This research was supported in part by National Institute of Mental Health Training Grant in Experimental Psychology MH-08359 and in part by the Bureau of General Research, Kansas State University. Reprints may, be obtained from Jerome Frieman. Dwight Walker is now at Smoky Mountain Mental Health Center, Cullowhee, North Carolina 28723.
There are three reasons why transfer following CER training would be of interest. First, all of the experiments cited above have examined the effects of various kinds of operant discrimination training with one set of stimuli upon the acquisition of a second operant discrimination. CER training, on the other hand, is a form of Pavlovian conditioning, since the presentation of the US (in this case shock) is independent of the subject's behavior. While there have been a number of studies reported in which Pavlovian differential conditioning was found to facilitate subsequent operant performance (Bower \& Grusec, 1964; Mellgren \& Ost, 1969; Ost \& Mellgren, 1970; Trapold, Lawton, Dick, \& Gross, 1968), in those experiments the same stimuli were used in both the Pavlovian and operant phases of the experiment. In the present study, the CER training involved different stimuli.

Another way in which the use of CER departs from the previous studies of transfer across stimulus dimensions is that CER is an aversive conditioning procedure, while all of the other studies involved appetitive conditioning only. While transfer of control by a stimulus dimension has been studied across motivating conditions (e.g., Trapold \& Overmeier, 1972), this is the first experiment reporting transfer across stimulus dimensions. The third reason for studying transfer following CER training is that the subject can do nothing to escape or avoid shock in CER. A substantial body of literature indicates that under certain conditions learning is impaired by exposure to unavoidable shock. For example, in the "learned helplessness" experiments (e.g., Maier, Seligman, \& Solomon, 1969), exposure to inescapable shock was found to impede the learning of escape-avoidance responses. Likewise, the introduction of inescapable shock has been found to disrupt ongoing appetitive discrimination performance (Brimer \& Wickson, 1971; Hearst, 1965). Thus, it is reasonable to expect that CER training might also retard the acquisition of a new discrimination. 


\section{METHOD}

\section{Subjects}

Experimentally naive White King pigeons of various ages, obtained from a local supplier, served as subjects. All birds were reduced to approximately $70 \%-75 \%$ of their ad-lib weight and maintained at that level throughout the experiment.

\section{Apparatus}

Two identical operant conditioning chambers, described in detail elsewhere (Keilitz \& Frieman, 1970), were used. In each chamber an Industrial Electronics display cell equipped with a Kodak Wratten filter (No.99) and illuminated by a GE 44 miniature lamp projected a chromatic stimulus of $555 \mathrm{~nm}$ onto the response key. The conditioned stimulus (CS) consisted of a vertical (90-deg) white line, $.32 \mathrm{~cm}$ wide $\times 2.22 \mathrm{~cm}$ high, projected onto the response key by the display cell and superimposed on the 555-nm light. Additional illumination in the experimental chambers was provided only by the grain hopper light during grain access periods. Auditory stimuli consisting of either white noise (produced by a homemade generator) or a $1,000-\mathrm{Hz}$ tone (produced by a Hewlett-Packard audio oscillator $200 \mathrm{AB}$ ) were introduced into each chamber through 4-in. speakers at the appropriate times. Associated programming equipment was located outside the experimental room.

Electric shock (1.3 mA) was supplied by a constant-current shock source (Grason-Stadler shock generator E1064GS) and administered via wing bands according to the method developed by Hoffman (1960). These bands were standard nickel-plated bead chain, $.3 \mathrm{~cm}$ in diam and wrapped once around the base of each wing. To facilitate delivery of the shock, a flexible connector, $20 \mathrm{~cm}$ in length, was clipped to the wing bands and joined to the shock source through a standard telephone jack centered in the chamber ceiling.

\section{Procedure}

Four groups were derived by random assignment of six subjects per group. On the day of initial food deprivation, wing bands were attached to all subjects to allow adaptation prior to preliminary training and remained in place through Phase 1.

Preliminary training. On Day 1 all subjects were magazine trained, shaped to peck the key, and reinforced for every response until 40 reinforcements of 4-sec access to the grain hopper (containing mixed wheat and milo) had been obtained. The following day every response was again reinforced until 40 more reinforcements were collected. On Day 3 every 10th response was reinforced (FR 10) and the ratio was increased to FR 20 on Day 4. A variable interval (VI) 30 -sec schedule was introduced on Day 5 , followed by 5 days during which a VI 90-sec (range: 28-141 sec) schedule was in effect. Throughout preliminary training each daily session continued until 40 reinforcements had been obtained by each subject. The response key, illuminated by the $555-\mathrm{nm}$ stimulus for all subjects, was darkened only during all periods of food access.

Phase 1. Differential treatment of groups was introduced on the day following preliminary training. Birds in the CER group were exposed to five 2-min presentations of the CS (white vertical lines superimposed on a $555-\mathrm{nm}$ surround) programmed to occur on a VT 12-min schedule (inter-CS time range: $8 \mathrm{~min} 7 \mathrm{sec}$ to $15 \mathrm{~min} 55 \mathrm{sec}$ ). Throughout the approximately 60 -min session, operant keypecking was maintained on a VI $90-\mathrm{sec}$ schedule of food presentation. A $1.3-\mathrm{mA}$ shock of $1-\mathrm{sec}$ duration was presented simultaneously with each CS termination for subjects in the CER group. Suppression training for each subject in this group continued until a criterion of 3 consecutive days was reached, during which the mean daily suppression ratio (see Kamin, 1969) for individual subjects was .1 or less.

Each subject in the NS, CS-alone, and US-alone groups was randomly paired with a subject in the CER group and given
Phase 1 training until the yoked CER subject reached criterion. All subjects in the NS group continued to receive keypeck training on the VI 90-sec schedule with no presentations of either the CS or US. Subjects in Group CS-alone were given five presentations of the 2-min CS occurring on the VT 12-min schedule, but no shocks were presented to this group. In the US-alone group, all subjects received five random presentations of the US according to the schedule used for the CER subjects, but no CS exposure was given to subjects in this group.

In each condition in which shock presentations occurred, subjects were allowed to recover keypeck responding (at least 20 pecks during the 2 -min pre-CS period) before the next presentation of the CS or US was given. Additionally, during each daily session, subjects were allowed to commence pecking before the initial CS or US presentation was given. Regardless of condition, food presentation was programmed according to the VI 90-sec schedule; however, CS termination automatically cancelled any reinforcement which was primed during the CS presentation but not obtained because of a lack of keypecking during the CS. Again, the key light was darkened during all reinforcement periods.

Phase 2. The next phase of the experiment, which consisted of discrimination training between two auditory stimuli, was identical for all four groups. A $1,000-\mathrm{Hz}$ tone and white noise were counterbalanced within groups as either the positive or negative stimulus. Responses in the presence of the positive stimulus ( $\mathrm{S}+$ ) were reinforced on a VI 30 -sec schedule and extinction was in effect during the presence of the negative stimulus (S-). The response key continued to be illuminated by the 555-nm light except during periods of grain access.

Each session of discrimination training consisted of 20 stimulus periods of 2-min duration separated by 10 -sec blackout periods. All subjects were given 10 daily training sessions, each consisting of two blocks of 10 stimulus periods. During each block of stimulus presentation, both $\mathrm{S}+$ and $\mathrm{S}-$ were presented five times in a quasirandom order, with the restriction that no more than two identical stimulus periods appeared successively.

\section{RESULTS}

\section{Phase 1}

Of the six subjects in the CER group, two reached the criterion of a mean daily suppressive ratio of .1 or less in 3 days, two in 4 days, and two in 5 days. The subjects in the three comparison groups were matched with subjects in the CER group and were maintained in Phase 1 until the CER pair-mate reached criterion.

\section{Phase 2}

All subjects were maintained on the auditory discrimination for 10 consecutive days. For each subject on each day, an index of discriminative performance was computed by dividing the number of responses emitted in the presence of $\mathrm{S}+$ by the total responses (i.e., responses in the presence of both $\mathrm{S}+$ and $\mathrm{S}-$ ). With this index, a lack of discrimination on the part of the subjects would be reflected by a score around .50 . Perfect discrimination would be reflected in a score of 1.00 .

In Figure 1, where the mean daily index scores for all four groups are presented, it can be seen that the CER group learned the auditory discrimination at a faster rate and reached a higher level of discriminative performance at the end of Phase 2 than did the subjects in the other three groups. A 4 by 2 by 10 analysis of 


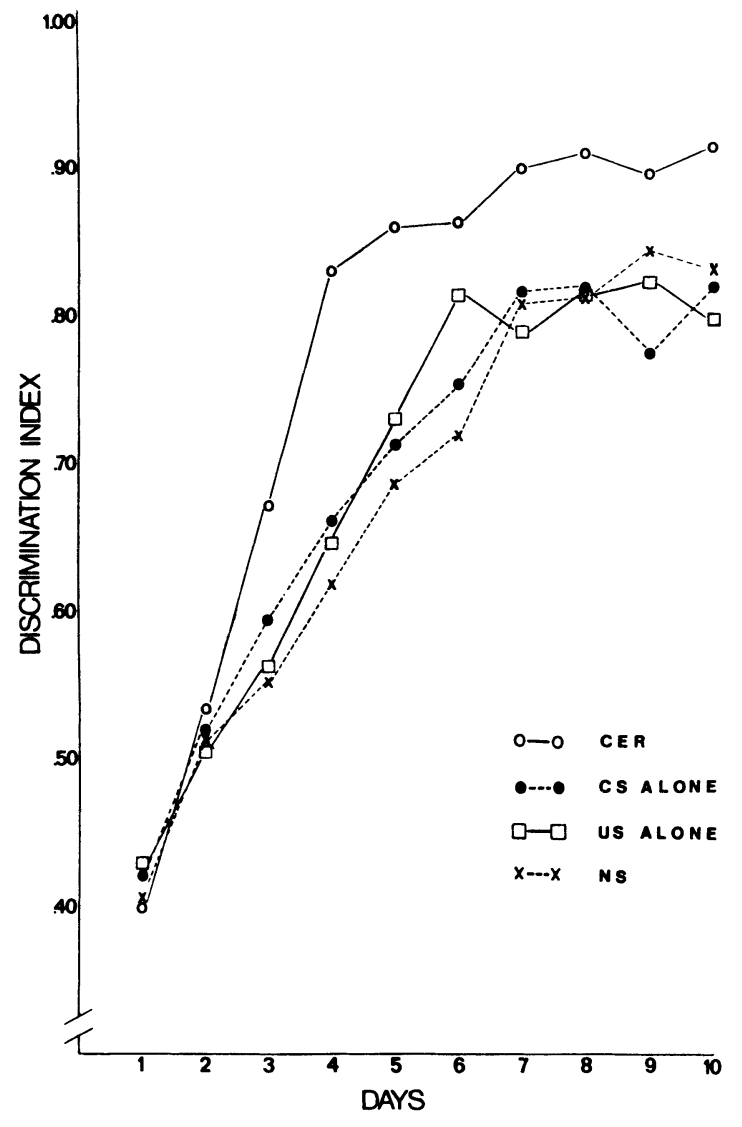

Figure 1. Mean discrimination index scores as a function of days in Phase 2.

variance (groups by positive stimulus by days) of the index scores revealed statistically reliable groups $[F(3,16)=3.576, \quad p<.05]$ and days $[F(9,144)=$ $118.680, p<.001]$ effects. All other main effects and interactions were not significant. Newman-Keuls comparisons of the mean group index scores revealed that the mean of the CER group differed reliably from the means of the other three groups. All other comparisons among the groups were not statistically reliable.

\section{DISCUSSION}

The major outcome of the present experiment is the demonstration that subjects given CER training acquire a subsequent successive operant discrimination problem faster and manifest a higher level of performance on that discrimination than do subjects who do not receive such training prior to the transfer task. This finding of positive transfer following conditioning with aversive control in a Pavlovian procedure represents a significant extension of the generality of conditions which facilitate the acquisition of a subsequent operant discrimination task involving a different stimulus dimension.

Two explanations can be advanced to account for results of this experiment. Thomas $(1969,1970)$ suggested that positive transfer is produced by the acquisition of a "general attentiveness" or "tendency to attribute significance to stimulus differences" during initial training. According to Thomas, during differential training the subject is assumed to (1) learn that external stimuli signify events or contingencies which are important for the welfare of the organism and (2) attach different responses to different stimuli. Therefore, subjects given such differential training during initial learning have already learned to attend to external stimulus differences, and have only to associate the appropriate response to the new relevant stimuli during subsequent discrimination problems. On the other hand, subjects not given such prior training must learn the significance of stimulus differences as well as attach the appropriate responses to the different stimuli. Consequently, the acquisition of subsequent discrimination learning is facilitated by prior discrimination training.

In the case of prior CER training, it might be argued that CER training also teaches subjects to attend to stimulus differences (CS presence vs CS absence). Consequently, these subjects, who are already attending to stimulus differences, would have only to associate the appropriate responses to the new discriminative stimuli in the transfer problem. Response rate reduction in the presence of $\mathrm{S}$ - during this discrimination would occur rapidly. In contrast, subjects in the NS, CS-alone, and US-alone groups would not have learned to attend to stimulus differences in Phase 1. Therefore, these subjects would continue to respond to the negative stimulus because they must first learn about attention to stimulus differences before attaching the appropriate response tendency to each stimulus.

The second explanation of the positive transfer effect involves the concept of learning to withhold responses. This explanation is based on the fact that, in order to master a successive go/no-go discrimination, subjects must learn to withhold responses in the presence of the negative stimulus. Thus, it could be argued that when transfer is studied over two successive discriminations, this learned response tendency (acquired during the first discrimination) is the primary factor responsible for the transfer effect. In the present experiment, only the CER subjects had to suppress responding in order to demonstrate learning in Phase 1, and these were the subjects who exhibited the fastest acquisition of the auditory discrimination in Phase 2.

The data from the present experiment cannot help one differentiate between these two explanations. To do so, one would have to design an experiment in which subjects either had no opportunity to learn about stimulus differences or no opportunity to learn to withhold responses. While attempts have been made to eliminate these two possibilities experimentally (Goyette, 1973; Goyette \& Frieman, 1973), in both studies the positive transfer effect was obtained. It may be that both explanations describe the sufficient (but not necessary) conditions for the facilitation of successive operant discrimination performance.

Finally, a comment about the design of the present experiment seems appropriate. Rescorla (1967) has argued that the appropriate control procedure for Pavlovian conditioning is what he calls the "random control." In this procedure, the CS and US are presented in a random or uncorrelated fashion so that the probability of a US occurring in the presence of the CS is identical to the probability of a US occurring in the absence of the CS. In the present study it was not possible to run such a group because all subjects were allowed to recover responding before either the CS or (in the case of the US-alone group) the US was presented. This was done to provide accurate measurement of conditioning in the CER group. Without such measurement, we would have had no way of knowing if a lack of differences in performance in Phase 2 was due to poor experimental control in Phase 1. Because the intertrial intervals (i.e., non-CS periods) depended on the subject's behavior, it was not possible to arrange ahead of time equal probabilities of US presentations in the presence and absence of the CS. It was felt that the accurate measurement of conditioning was more 
important than this control procedure. It was assumed that the other groups (CS alone, US alone, NS) would provide adequate comparison conditions.

\section{REFERENCES}

Bower, G., \& Grusec, T. Effect of prior Pavlovian discrimination training upon learning an operant discrimination. Journal of the Experimental Analysis of Behavior, 1964, 7, 401-404.

Brimer, C. S., \& Wickson, S. Shock frequency, disinhibition, and conditioned suppression. Learning and Motivation, 1971, 2, 124-137.

Eck, K. O., Noel, R. C., \& Thomas, D. R. Discrimination learning as a function of prior discrimination and nondifferential training. Journal of Experimental Psychology, 1969, 82, 156-162.

Frieman, J., \& GoYetTe, C. H. Transfer of training across stimulus modality and response class. Journal of Experimental Psychology, 1973, 97, 235-241.

GoyetTe, C. H. Transfer of training, general attention, and learned response tendencies. Unpublished PhD dissertation. Kansas State University, Manhattan, Kansas, 1973.

Goyette, C. H., \& Frieman, J. Transfer of training following discrimination learning with two reinforced responses. Learning and Motivation, 1973, 4, 432-444.

HeARST, E. Stress-induced breakdown of an appetitive discrimination. Journal of the Experimental Analysis of Behavior, 1965, 8, 135-146.

Hoffman, H. S. A flexible connector for delivering shock to pigeons. Journal of the Experimental Analysis of Behavior, $1960,3,330$.

Kamin, L. J. Selective association and conditioning. In N. J. Mackintosh \& W. K. Honig (Eds.), Fundamental issues in associative learning. Halifax: Dalhousie University Press, 1969.

KeIlitz, I., \& Frieman, J. Transfer of training following errorless discrimination learning. Journal of Experimental Psychology, 1970, 85, 293-299.

Maier, S. F., Seligman, M. E. P., \& Solomon, R. L. Pavlovian fear conditioning and learned helplessness:
Effects on escape and avoidance behavior of (a) the CS-US contingency and (b) the independence of the US and voluntary responding. In B. A. Campbell \& R. M. Church (Eds.), Punishment and aversive behavior. New York: Appleton-Century-Crofts, 1969.

Mellgren, R. L., \& Ost, J. W. Transfer of Pavlovian differential conditioning to an operant discrimination. Journal of Companative and Physiological Psychology, 1969, 67, 390-394.

Ost, W. P., \& Mellgren, R. L. Transfer from Pavlovian differential to operant discriminative conditioning: Effect of amount of Pavlovian conditioning. Journal of Comparative and Physiological Psychology, 1970, 71, 487-491.

Rescorla, R. A. Pavlovian conditioning and its proper control procedures. Physiological Review, 1967, 74, 71-80.

Tennant, W. A., \& Bitterman, M. E. Extradimensional transfer in the discriminative learning of goldfish. Animal Learning \& Behavior, 1975, 3, 201-204.

Thomas, D. R. The use of operant conditioning techniques to investigate perceptual processes in animals. In R. $M$. Gilbert \& N. S. Sutherland (Eds.), Animal discrimination learning. London: Academic Press, 1969.

Thомas, D. R. Stimulus selection, attention, and related matters. In J. H. Reynierse (Ed.), Current issues in animal learning. Lincoln: University of Nebraska Press, 1970.

Thomas, D. R., Miller, J. T., \& Svinicki, J. G. Nonspecific transfer effects of discrimination training in the rat. Journal of Comparative and Physiological Psychology, 1971, 74, 96-101.

Trapold, M. S., Lawton, G. W., Dick, R. A., \& Gross, D. M. Transfer of training from differential classical to differential instrumental conditioning. Journal of Experimental Psychology, 1968, 76, 568-573.

Trapold, M. A., \& Overmeier, J. B. The second learning process in instrumental learning. In A. H. Black \& W. F. Prokasy (Eds.), Classical conditioning II: Current research and theory. New York: Appleton-Century-Crofts, 1972.

(Received for publication January $12,1977$. ) 